\title{
Alejandro Rabinovich, Anatomía del pánico. La batalla de Huaqui, o la derrota de la revolución (1811), Buenos Aires, Sudamericana, 2017
}

DOI: http://dx.doi.org/10.15648/hc.36.2020.12

Alejandro Rabinovich doctor en Historia y Civilizaciones por la Escuela de Altos Estudios en Ciencias Sociales de París nos presenta un nuevo texto fundamental para la historia militar, Anatomía del pánico. La batalla de Huaqui, o la derrota de la revolución (1811). Es un libro que busca conocer los gestos y las acciones de los jefes, oficiales y soldados que protagonizaron la catastrófica desbandada. Comprender estas acciones permite discernir el actuar de los soldados en los campos de batalla y el rol que tuvo el pánico en los combates del siglo diecinueve. La tesis central propone que los ejércitos revolucionarios no fueron deshechos por el accionar de las fuerzas realistas, ni por las muertes de sus militares. Como indica Rabinovich "simplemente, en un momento dado, se desató una fulgurante ola de pánico que recorrió las filas del ejército hasta deshacerlas por completo. Los efectos de este pánico fueron tan devastadores que, incluso varios después de la batalla, a decenas de kilómetros del enemigo y cuando ya no corrían ningún peligro, las tropas seguían huyendo sin que los oficiales y autoridades locales lograran detenerlas".

Estas ideas son recogidas por los cinco capítulos que componen la obra: en el primero, un ejército revolucionario se habla de la conformación del ejército nacional, sus primeras batallas contra las tropas realistas en Córdoba, su marcha al Alto Perú para derrocar al virreinato español, la organización militar de los ejércitos del rey, la formación del Ejército Auxiliar y Combinado del Perú; a continuación, el capítulo 2, la opción

1 Alejandro Rabinovich, Anatomía del pánico. La batalla de Huaqui o la derrota de la revolución (1811) (Buenos Aires: Sudamericana, 2017), 12. 
por la batalla se estudia la preparación de la tropa revolucionaria antes de Huaqui, su motivación, la instrucción y la capacidad que tuvieron los soldados en el espacio de vida guerrero y así descubrir cómo y por qué se desató el pánico, Balcarce y Castelli responsabilizan al Regimiento $\mathrm{n}^{\circ} 6$ de haber iniciado el pánico que se terminó extendiendo a todo el ejército en la batalla de Huaqui, el capítulo 3, un día de combate, el autor se detiene en la visión de los ejércitos sobre lo acontecido en la batalla del Huaqui, Rabinovich explica que "los agentes de su propagación fueron los gritos, los rumores y los dispersos que venían siempre desde los cerros, estos desencuentros permitieron que el pánico encontrara su lugar en el campo de batalla ." ${ }^{2} \mathbf{E} 1$ pánico en acción, es el título del capítulo 4, aquí se analiza profundamente la derrota del Ejército Auxiliar del Perú, las roturas de las propias piezas de artillería ocasionaron que las tropas perdieran la confianza, a pesar de los esfuerzos de sus generales por motivar a sus soldados a que mantuvieran la calma, el pánico los terminó absorbiendo y huyeron a refugiarse tras grandes piedras, congelados y muchos perdieron la noción de lo que sucedía. La dinámica de un desastre total, este capítulo cierra el libro, finalmente, Rabinovich se concentra en realizar una reflexión y análisis personal de lo que significó la batalla de Huaqui. El pánico suscitado en ese enfrentamiento dejo graves consecuencias, la derrota de los ejércitos revolucionarios frente a las tropas realistas, la muerte de 1\% de militares de las fuerzas independentistas y finalmente la brutal dispersión generada por el pánico de Huaqui que significó la disolución del ejército. Una vez cesado el combate, el pánico se apodera de los combatientes, empiezan a desertar de las filas patriotas dirigiéndose al Cerrito de los paceños, no había motivación ni deseos de enfrentarse a los ejércitos del rey, los soldados patriotas temían encontrarse con los realistas huyendo a los cerros altoperuanos.

En este contexto, nos parece que Anatomía del pánico contiene tres puntos generales que resumen sus principales ideas. El primer tema tiene relación con las consecuencias sobre la moral del ejército después de la derrota en Huaqui. La experiencia sucesiva de pánicos podía romper 314 el espíritu de los soldados de seguir en combate y de pertenecer al ejér-

2 Alejandro Rabinovich, Anatomía del pánico. La batalla 15. 
cito independentista tras haber sido vencidos. Las autoridades militares tuvieron que disolver el batallón derrotado, Rabinovich comenta "esta separación duró días, semanas y hasta meses, resultó imposible reconstruir unidades operativas a partir de sus restos". ${ }^{3}$ El Estado buscaba comprender las causas de las derrota y de asignar responsabilidades, el comportamiento de los oficiales fue claramente criticado por las autoridades gubernamentales tras la derrota y la dispersión del ejército. El segundo punto general es el trabajo de Alejandro Rabinovich para reconstruir el pánico, no fue una actuación independiente, esto fue de todos los soldados, desarrollándose gracias a las interacciones entre ellas y sus encuentros fallidos. Los vehículos de propagación fueron los gritos y los rumores que venían siempre del otro lado del cerro, esto fue terreno fértil para que el pánico se propagara sobre todos los combatientes. El último punto es demostrar la importancia del "Cerro de las guerrillas" un pequeño y macizo montañoso, Rabinovich comenta que "un soldado venido de Buenos Aires, muerto de hambre y mal calzado, trepar los 80 metros del Cerro de las guerrillas luchando contra la falta de aire y soroche podía significar una empresa titánica." "Las ventajas de estas posiciones, era favorable para el ejército independentista, el Cerro de las guerrillas era el espacio donde se encontraba el campamento patriota, a unos 500 metros de distancia, la fusilería desde la cima del cerro llegaba a herirla levemente, aunque sin la más mínima precisión. La estrategia militar no resultó efectiva, las divisiones patriotas fueron vencidas por las guerrillas, las compañías de infantería tuvieron que haber apoyado a los soldados pero todo estaba perdido y fueron vencidos por el fuego de los cañones de Juan Pío de Tristán. La división de Viamonte había sido vencida, los que gritaban no solo eran los soldados, sino también la de un capitán.

Concluyo haciendo mención que el libro de Alejandro Rabinovich es completamente novedoso, el autor estudia en detalle las causas y consecuencias de este pánico que condujo a la pérdida del Alto Perú, sembrando inseguridades en torno al futuro mismo de la Revolución. Este trabajo tiene otra virtud, la extensa revisión de fuentes primarias encon-

3 Alejandro Rabinovich, Anatomía del pánico. La batalla 31.

4 Alejandro Rabinovich, Anatomía del pánico. La batalla 131. 
tradas en el Archivo General de la Nación de Argentina por nombrar algunos, Listas de Revistas, Estados de Fuerza, Solicitudes Militares, la revisión al Archivo de la Paz en Bolivia, Ejército Cajas, Cajas Reales, Expedientes Coloniales como también el Archivo del Ejército de Buenos Aires y el Archivo Particular del Conde de Guaqui. En definitiva, podemos asegurar que el texto de Alejandro Rabinovich es un nuevo impulso para los estudiosos de la guerra, convirtiéndose en una referencia obligada para quienes investigan este periodo, por los innumerables datos que aportan desde lo militar, psicológico, político y social.

\author{
Jorge Orellana Billiard. \\ Programa de Doctorado en Historia, \\ Pontificia Universidad Católica de Valparaíso. \\ jorgeorellana150@gmail.com
}

